\title{
Improvement of Prepulse Inhibition and Executive Function by the COMT Inhibitor Tolcapone Depends on COMT Val I58Met Polymorphism
}

\author{
Stella G Giakoumaki ${ }^{1,2}$, Panos Roussos ${ }^{1,2}$ and Panos Bitsios*,1 \\ 'Department of Psychiatry and Behavioral Sciences, Faculty of Medicine,University of Crete, Heraklion, Greece
}

Recent evidence suggests that prepulse inhibition (PPI) levels relate to executive function possibly by a prefrontal cortex (PFC) dopamine (DA) link. We explored the effects of enhanced PFC DA signaling by the nonstimulant catechol-O-methyltransferase (COMT) inhibitor tolcapone, on PPI and working memory of subjects homozygous for the Val (low PFC DA) and the Met (high PFC DA) alleles of the COMT Val I 58Met polymorphism. Twelve Val/Val and eleven Met/Met healthy male subjects entered the study. Tolcapone $200 \mathrm{mg}$ was administered in two weekly sessions, according to a balanced, crossover, double-blind, placebo-controlled design. PPI was assessed with $5 \mathrm{~dB}$ and $15 \mathrm{~dB}$ above background prepulses, at 30-, 60-, and 120 ms prepulse-pulse intervals. Subjects also underwent the n-back and the letter-number sequencing (LNS) tasks. PPI was lower in the Val/Val compared to the Met/Met group in the placebo condition. Tolcapone increased PPI significantly in the Val/Val group and tended to have the opposite effect in the Met/Met group. Baseline startle was not affected by tolcapone in the $\mathrm{Val} / \mathrm{Val}$ group but it was slightly increased in the Met/Met group. Tolcapone improved performance in the n-back and LNS tasks only in the Val/Val group. Enhancement of PFC DA signaling with tolcapone improves both PPI and working memory in a COMT Val I58Met genotype-specific manner. These results suggest that early information processing and working memory may both depend on PFC DA signaling, and that they may both relate to PFC DA levels according to an inverted U-shaped curve function.

Neuropsychopharmacology (2008) 33, 3058-3068; doi: I0.I038/npp.2008.82; published online 4 June 2008

Keywords: prepulse inhibition; sensorimotor gating; prefrontal cortex; dopamine; cognition; working memory

\section{INTRODUCTION}

The enzyme catechol-O-methyltransferase (COMT) is the main catabolic pathway by which dopamine (DA) is removed from the cortical synaptic cleft in humans (Karoum et al, 1994). Indeed, COMT is found in high concentrations in the cortex relative to subcortical regions (Matsumoto et al, 2003) consistent with the absence of functional DA transporters in cortical areas such as the prefrontal cortex (PFC) and hippocampus (Mazei et al, 2002). The Val158Met polymorphism in the COMT gene leads to an amino-acid substitution (valine (Val) to methionine (Met)) and results in the Met/Met variant showing $40 \%$ less enzymatic activity than the Val/Val (Chen et al, 2004). There is now abundant evidence (reviewed in Harrison and Weinberger, 2005; Tunbridge et al, 2006) that

*Correspondence: Dr P Bitsios, Department of Psychiatry and Behavioral Sciences, Faculty of Medicine, University of Crete, PO BOX 2208, Stavrakia-Voutes, Heraklion, Crete 7I003, Greece,

Tel: + 302810394610 , Fax: + 302810394610 ,

E-mail: pbitsios@med.uoc.gr

${ }^{2}$ These authors contributed equally to this work.

Received 27 March 2008; accepted 7 May 2008
Met158 allele loading is dose dependently associated with superior performance on a variety of cognitive tests assessing executive function, as well as prefrontal physiology as assessed by neuroimaging. The evidence suggests that PFC DA facilitates 'focusing and stabilizing' activity in PFC networks during executive cognition, ie enhances prefrontal physiologic 'efficiency' by reduction of prefrontal noise (Cools et al, 2002; Mattay et al, 2002, 2003).

Prepulse inhibition (PPI) is thought to reflect 'sensorimotor gating', a form of central nervous system inhibition wherein irrelevant sensory information is filtered out during the early stages of processing so that attention can be focused on more salient features of the environment (Braff et al, 1978). A large number of studies have shown that individuals with schizophrenia show reduced PPI (Braff et al, 2001, 2005; Swerdlow et al, 2006; Kumari et al, 2007). The sensory overload resulting from reduced sensorimotor gating is thought to give rise to cognitive fragmentation, attentional deficits, and some of the complex clinical symptoms associated with this disorder (Geyer et al, 1990). PPI in rodents is modulated by activity in a welldefined cortico-striato-pallido-pontine circuitry (Swerdlow et al, 1992, 2001), which has been confirmed by functional 
imaging studies in humans (Kumari et al, 2003, 2007; Postma et al, 2006; Campbell et al, 2007). PPI levels predict gray matter availability in frontal cortical areas in patients with schizophrenia (Kumari et al, 2008), which extends to the hippocampal, striatal, thalamic, and temporal regions in healthy subjects (Kumari et al, 2005). Consistent with these neuroimaging findings and the notion that sensorimotor gating is important in human cognition (Geyer et al, 1990), neuropsychological studies show that higher PPI levels predict superior performance on tasks that rely on the integrity and efficiency of PFC function (Bitsios and Giakoumaki, 2005; Bitsios et al, 2006; Giakoumaki et al, 2006; Csomor et al, 2008).

We have recently shown that COMT Val158 allele loading is associated with lower PPI levels in healthy men (Roussos et al, 2008a). We proposed that this may be due to low PFC DA transmission and increased prefrontal noise in Valloading subjects and/or that the Val158 allele may indirectly increase striatal dopaminergic function, thus reducing PPI, likely as downstream manifestation of reduction in cortical information processing. In any case, PFC DA transmission seems to be an important neural mechanism that modulates human PPI (Roussos et al, 2008a). The aim of the present study was to better understand the relationship among COMT, PPI, and executive function. To this end, we set out to explore the effect of increased cortical DA signaling by tolcapone, on PPI and PFC-dependent tasks, in subjects with either $\mathrm{Val} / \mathrm{Val}$ or Met/Met status.

Tolcapone is a nonstimulant drug, which penetrates the blood-brain barrier (Ceravolo et al, 2002) and potently inhibits brain COMT activity in vivo (Da Prada et al, 1991). COMT inhibition by tolcapone is thought to lead to relatively specific increases of PFC DA, as COMT has little impact on norepinephrine flux in PFC, possibly because of the abundance of functional norepinephrine transporters (Gogos et al, 1998; Tunbridge et al, 2004). Tolcapone improved executive function in healthy Val158 homozygotes who have lower PFC DA concentrations at baseline but worsened the performance of Met/Met individuals who have high PFC DA concentrations, and operate near or at ceiling levels at baseline (Apud et al, 2007). These effects are consistent with the increasingly accepted model of the inverted U-shaped relationship between PFC DA signaling and PFC function (Goldman-Rakic, 1998, Williams and Goldman-Rakic, 1995). On the basis of the assumption that PFC DA signaling is important for both PPI and PFC function, we predicted that tolcapone would improve PPI and executive function in Val/Val homozygotes; we also predicted that tolcapone would decrease or have no effect on PPI and cognitive function of Met158 homozygotes.

\section{MATERIALS AND METHODS}

\section{Subjects}

A total of 24 healthy male subjects were recruited from a cohort of 93 subjects who had participated in a study examining the effects of the COMT Val158Met polymorphism on PPI. Subjects were selected such as to form two equal homozygote groups (Val/Val, $n=12$ and Met/Met, $n=12$ ). The selection was random and based on subject availability. All subjects had previously undergone genotyping, thorough psychiatric and medical assessment including drug screening and audiometry (Roussos et al, 2008a), but they had a new urine toxicology screening prior to testing and their IQ was also assessed with the Raven's progressive matrices (Raven et al, 1977). The study was approved by the ethics committee of the University of Crete. All participants gave written informed consent before screening.

\section{Design and Drugs}

All subjects participated in two weekly sessions associated with either single, acute oral tolcapone $(200 \mathrm{mg})$ or placebo administration in identical capsules. Within each separate genotype group, subjects were allocated to sessions and treatments in a balanced, crossover, double-blind manner according to a Latin square design. After the baseline measurement of subjects' mood state with the Profile of Mood States (POMS) self-rated questionnaire (McNair and Lorr, 1981), the POMS was administered again $1.8 \mathrm{~h}$ posttreatment at the time of tolcapone's peak effect (Hardman et al, 2001) to assess drug-induced changes in mood or activation. This procedure was followed by PPI testing and neuropsychological assessment.

\section{Measurement of the Startle Response}

A commercially available electromyographic (EMG) startle system (EMG SR-LAB, San Diego Instruments, San Diego, CA, USA) was used to examine the eyeblink component of the acoustic startle response from the right orbicularis oculi muscle. Equipment descriptions, setup, and scoring criteria have been previously described in detail (Bitsios et al, 2005). We used a range of stimulus parameters designed to explore potential stimulus- or stimulus by genotype-dependent effects of the drug. Pulses consisted of $40 \mathrm{~ms}, 115 \mathrm{~dB}$ white noise bursts, and prepulses consisted of $20 \mathrm{~ms}, 75$ and $85 \mathrm{~dB}$ white noise bursts over $70 \mathrm{~dB}$ background noise. Recording began with $3 \mathrm{~min}$ acclimation period when only the background noise was present. The recording period consisted of 12 pulse-alone trials, 36 prepulse-pulse trials and 6 no-stimulus (NOSTIM) trials for the assessment of drug effects on basal EMG activity. Three lead intervals (onset to onset) were used $(30,60$, and $120 \mathrm{~ms})$. For each interval, there were six trials with the $75 \mathrm{~dB}$ prepulse and six trials with the $85 \mathrm{~dB}$ prepulse. All trials were presented in pseudorandom order with the constraint that no two identical trials occurred in succession. The intertrial interval varied between 9 and $23 \mathrm{~s}$ (average $15 \mathrm{~s}$ ). The entire test session lasted approximately $15 \mathrm{~min}$. Before scoring and data analysis, all recordings were screened for spontaneous eyeblink activity. Trials were excluded (3\% of trials across genotypes and treatment conditions) using published criteria (Braff et al, 1992). No subjects had more than three (out of six) trials per trial type discarded at any one session.

\section{Neuropsychological Testing}

Neuropsychological testing was carried out immediately after startle testing. The following tests were selected because they engage prefrontal cortical processes and have demonstrated sensitivity to COMT genotype: (1) n-back sequential letter task - the task consisted of four conditions 
(0-, 1-, 2-, and 3-back) where subjects were asked to respond by a button-press when they saw a target letter (letter ' $\mathrm{X}$ ' for 0 -back and any letter that was identical to the one presented in the preceding 1,2, or 3 trials, respectively). The outcome variables were the number of correct responses and reaction time. The n-back task is a working memory test allowing 'online' manipulation of information, demonstrated to engage a wide network of brain regions with dorsal PFC activation being the most consistent finding (Fletcher and Henson, 2001). (2) Letter-number sequencing (LNS; Wechsler, 1997) - subjects were asked to store and reorder (recite in numeric and alphabetical order) strings of intermingled letters and numbers with increasing difficulty. The outcome variable was the total number of correct strings. It is a test of working memory and overt manipulation of information, requiring subjects not only to store information but also to reorder it according to preset rules. Areas of activation include the orbital frontal lobe, dorsolateral PFC, and posterior parietal cortex (Haut et al, 2000).

\section{Statistical Analysis}

Demographic data (age, years of education, IQ) were compared between the groups using one-way analysis of variance (ANOVA). Pre-posttreatment changes in each POMS scale were calculated for the placebo and tolcapone treatment conditions and were compared using separate $2 \times 2$ (genotype $\times$ treatment) ANOVAs. The mean background EMG activity from the six NOSTIM trials in each treatment condition was subjected to separate $2 \times 2$ (genotype $\times$ treatment) ANOVAs. Startle data from the 12 pulse-alone trials were collapsed in four blocks of three trials each and the means of each block were subjected to a $2 \times 2 \times 4$ (genotype $\times$ treatment $\times$ block) ANOVA to examine genotype and treatment effects on startle amplitude and habituation. The maximal amplitudes of the raw EMG responses from each trial were averaged across all trials of the same type. Percentage PPI $\left(\%\right.$ PPI $=\left(\left(\right.\right.$ Amplitude pulse-alone $^{-}$ Amplitude $\left._{\text {prepulse-pulse }}\right) /$ Amplitude $\left.\left._{\text {pulse-alone }}\right) \times 100\right)$ ) and peak latency data were analyzed with $2 \times 2 \times 2 \times 3$ (genotype $\times$ treatment $\times$ prepulse $\times$ interval) ANOVAs. Performance variables from the neuropsychological tests were analyzed using four-way ANOVAs with genotype as the between- and treatment, difficulty level and order (drug then placebo or placebo then drug) as the within-subject factors. All repeated measures with more than two levels (or one degree of freedom) employed the Greenhouse-Geisser $\varepsilon$-correction. Uncorrected degrees of freedom are reported in this case, with the corrected $p$-values and the $\varepsilon$-value. Effect sizes (partial $\eta^{2}$ ) are also reported.

\section{RESULTS}

\section{Demographic Variables}

One Met/Met individual failed to complete the study and was therefore excluded from the analyses. The age, education in years, and IQ of the Val/Val group $(n=12)$ were (mean \pm SD) $26.6 \pm 3.9,17.9 \pm 2.8$, and $108.3 \pm 9.1$, respectively and for the Met/Met group $(n=11)$ were $24.6 \pm 2.8$, $16.8 \pm 2.1$, and $116.4 \pm 11.6$, respectively. ANOVA comparisons revealed no differences between the two genotype groups (age: $\mathrm{F}(1,21)=1.8, p>0.2$; education: $\mathrm{F}(1,21)=1.1, p>0.3$; IQ: $\mathrm{F}(1,21)=3.4, p>0.08)$. The smokers/nonsmokers ratio was $6 / 6$ for the $\mathrm{Val} / \mathrm{Val}$ and $2 / 9$ for the Met/Met groups $\left(\chi^{2}=2.6, p>0.1\right)$.

\section{Subjective Ratings}

Figure 1 shows the post-pretreatment changes in the seven items of the POMS ratings for the two genotype groups and the two treatment conditions. Separate $2 \times 2$ (treatment $\times$ genotype) ANOVAs of the pre-posttreatment changes in the POMS ratings did not reveal any significant main effect of treatment, genotype, or their interaction in any of the POMS items (all $p$-values $>0.18$ ).

\section{Basal EMG Activity and Startle Latency: Amplitude and Habituation}

Table 1 shows the background EMG activity, and startle characteristics of the two genotype groups for the two treatment conditions. There was no main effect of genotype or treatment or significant interaction on background EMG activity and on startle onset and peak latencies (all $p$-values $>0.16$ ). There were no effects of smoking status on these variables. A $2 \times 2 \times 4$ (treatment $\times$ genotype $\times$ block ANOVA of startle in pulse-alone trials showed significant main effects of block indicating habituation $(\mathrm{F}(3,63)=7.6$, $p<0.001, \varepsilon=0.789$, linear trends: $\mathrm{F}(1,21)=21.4, p<0.001)$, but not treatment $(\mathrm{F}(1,21)=2.9, p>0.1)$ or genotype $(\mathrm{F}(1,21)=3.7, p=0.07))$. The treatment by genotype interaction was significant $(\mathrm{F}(1,21)=5.0, p<0.037)$. None of these effects was altered when smoking status entered as an additional grouping factor (smoking status main effect: $\mathrm{F}<1$; no interactions). Follow-up ANOVAs within each genotype group showed a trend level increase in startle by tolcapone in the case of the Met/Met (treatment main effect: $\mathrm{F}(1,10)=3.9, p=0.076$ ) but not the $\mathrm{Val} / \mathrm{Val}$ group (treatment main effect: $\mathrm{F}<1$ ).

\section{Prepulse Inhibition}

Figure 2 shows that compared to placebo tolcapone had opposite effects on \%PPI in the two genotype groups. An overall $2 \times 2 \times 2 \times 3 \quad$ (genotype $\times$ treatment $\times$ prepulse $\times$ interval) ANOVA revealed a significant treatment $\times$ genotype interaction $\left(\mathrm{F}(1,21)=16.1, p<0.001, \eta^{2}=0.434\right)$, reflecting the opposite effects of tolcapone in the two genotype groups. There were also significant main effects of prepulse $\left(\mathrm{F}(1,21)=64.1, p<0.001, \eta^{2}=0.753\right)$ and interval $\left(\mathrm{F}(2,42)=40.6, p<0.001, \eta^{2}=0.659, \varepsilon=0.721\right)$ (all other $p$-values $>0.1$ ). Because of trend genotype effects on baseline startle and IQ and treatment effects on baseline startle, we repeated the analysis with baseline startle and IQ as covariates. The ANCOVA showed that the critical treatment by genotype interaction remained significant $(\mathrm{F}(1,18)=$ $\left.15.2, p<0.001, \eta^{2}=0.457\right)$. None of the effects above was altered when smoking status entered as an additional grouping factor (smoking status main effect: $\mathrm{F}<1$; no interactions). The significant treatment $\times$ genotype interaction was followed up by $2 \times 2 \times 3$ (treatment by prepulse by interval) ANOVAs within each genotype group; these 

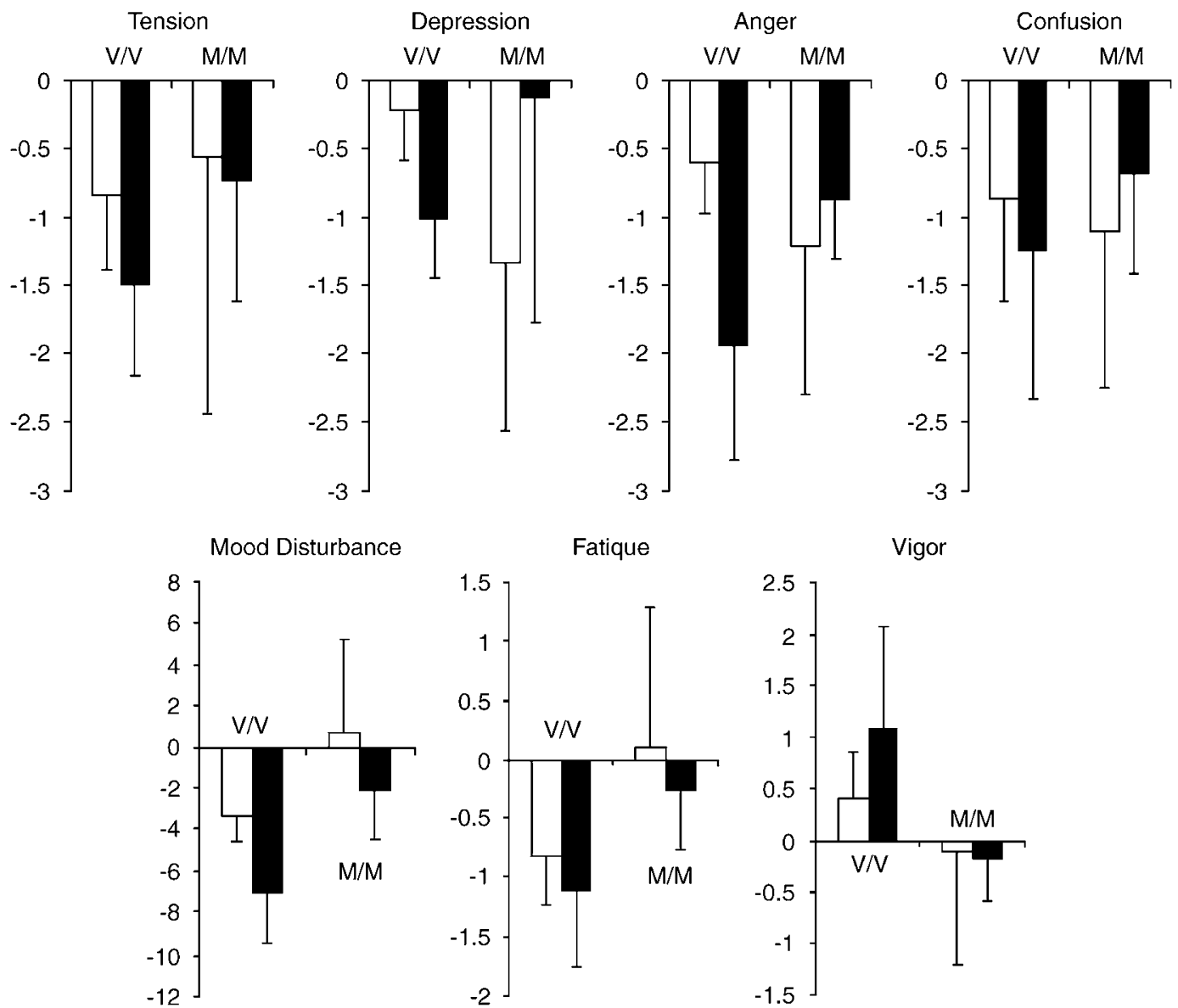

Figure I Post-pretreatment changes in ratings of the Profile of Mood States (POMS) items for the two genotype groups under the two treatment conditions. Bars represent SEM.

Table I Startle Characteristics (mean \pm SD) for the Two Genotype Groups Under the Two Treatment Conditions

\begin{tabular}{|c|c|c|c|c|}
\hline & \multicolumn{2}{|c|}{ Val/Val } & \multicolumn{2}{|c|}{ Met/Met } \\
\hline & Placebo & Tolcapone & Placebo & Tolcapone \\
\hline Mean pulse-alone startle $(\mu \vee)$ & $248.3 \pm 151$ & $239.6 \pm 155$ & $355.2 \pm 219$ & $422.6 \pm 219$ \\
\hline Startle onset latency (ms) & $44.4 \pm 4.3$ & $45.6 \pm 6.7$ & $41.8 \pm 6.1$ & $42.1 \pm 4.8$ \\
\hline
\end{tabular}

Abbreviation: EMG, electromyographic.

revealed that tolcapone significantly increased PPI in the $\mathrm{Val} / \mathrm{Val}$ group (treatment main effect: $\mathrm{F}(1,11)=14.1$, $p<0.003)$. In the Met/Met group tolcapone reduced PPI at trend level $(\mathrm{F}(1,10)=3.7, p=0.082)$.

PPI levels were greater in the placebo treatment condition for the Met/Met compared to the Val/Val group as evidenced by a $2 \times 2 \times 3$ (genotype $\times$ prepulse $\times$ interval) ANOVA for the placebo data only (Figure 2 ). This analysis revealed main effects of prepulse $(\mathrm{F}(1,21)=74.2, p<0.001$, $\left.\eta^{2}=0.779\right)$, interval $(\mathrm{F}(2,42)=23.0, \quad p<0.001, \quad \varepsilon=0.8$, $\left.\eta^{2}=0.522\right)$, and genotype $\left(\mathrm{F}(1,21)=6.2, p<0.02, \eta^{2}=\right.$ $0.229)$. There were no differences in startle amplitude in the placebo condition between the two genotype groups $(\mathrm{F}(1,21)=1.9, p>0.18)$.

\section{Prepulse Latency Facilitation}

Figure 3 shows the peak latency data of the two genotype groups for the two treatments. The overall $2 \times 2 \times 3$ (treatment $\times$ prepulse $\times$ interval) ANOVA of the peak latency data revealed significant main effects of prepulse $\left(\mathrm{F}(1,21)=45.5, \quad p<0.001, \quad \eta^{2}=0.684\right) \quad$ and interval $\left(\mathrm{F}(2,42)=11.8, p<0.001, \varepsilon=0.699, \eta^{2}=0.359\right)$ but not of treatment or genotype $(\mathrm{Fs}<1)$. There was a significant 


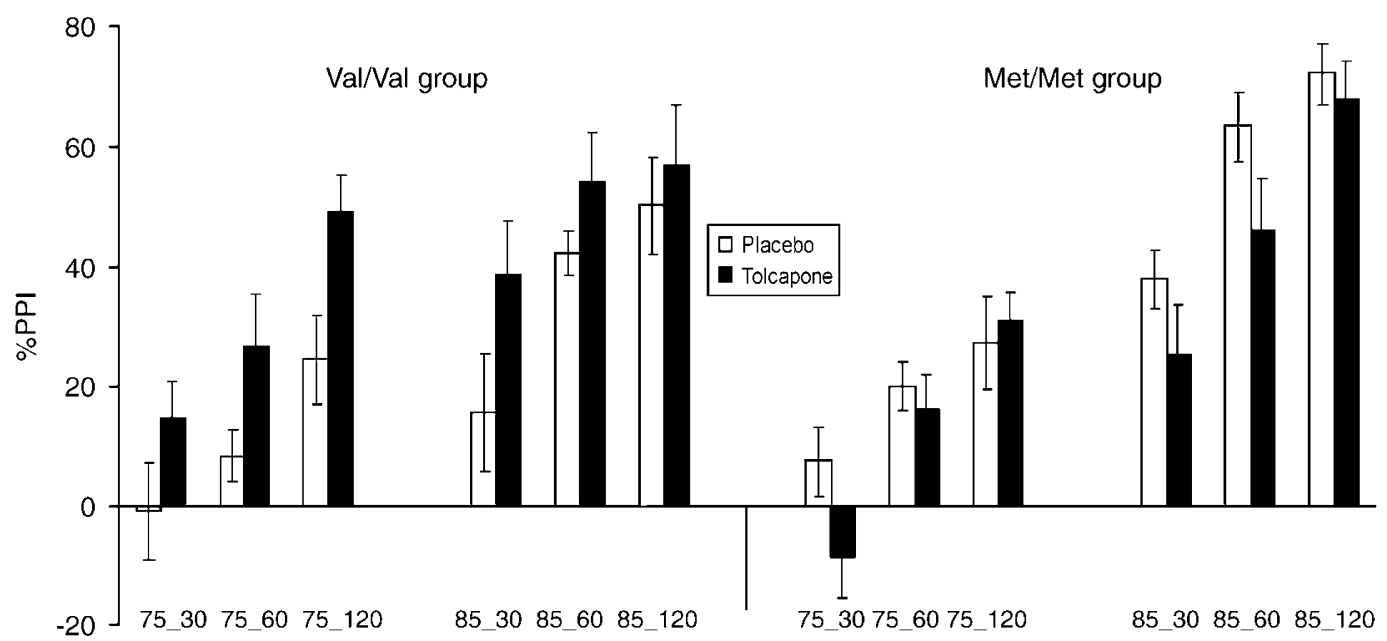

Figure 2 Percent prepulse inhibition (\%PPI) for the two genotype groups under the two treatment conditions. Bars represent SEM.

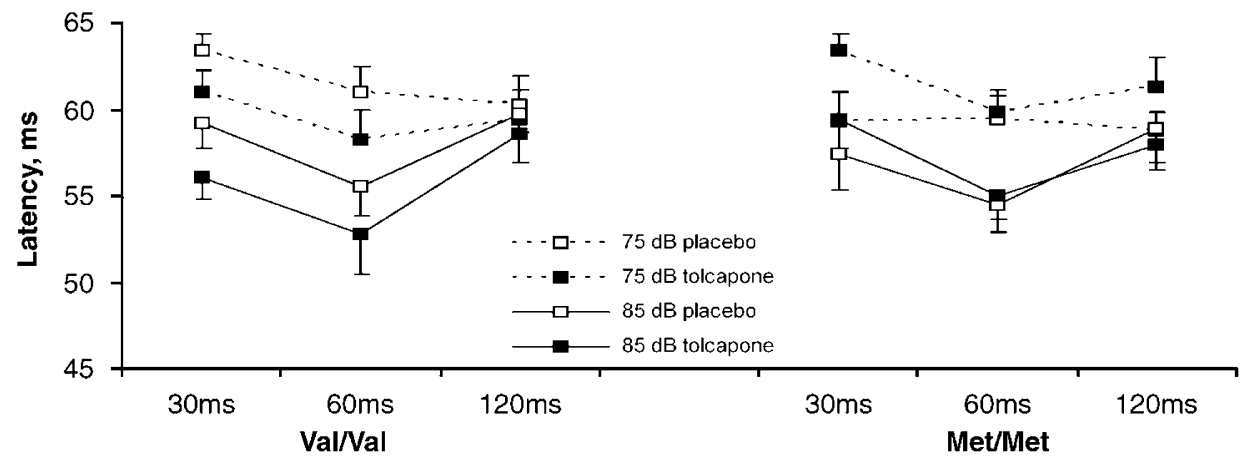

Figure 3 Peak latencies in prepulse-pulse trials for the two genotype groups under the two treatment conditions. Bars represent SEM.

treatment $\times$ genotype interaction $(\mathrm{F}(1,21)=6.7, p<0.02$, $\left.\eta^{2}=0.242\right)$. Follow-up of this interaction with separate ANOVAs within each genotype group showed a significant treatment main effect in the case of the Val/Val $(\mathrm{F}(1,11)=$ $5.9, p<0.033)$ but not the Met/Met group $(\mathrm{F}(1,10)=1.8$, $p>0.2)$.

\section{Neuropsychological Tests}

$N$-back. Reaction times: Figure 4 (top) shows the reaction times for both groups under the two treatment conditions. The overall $2 \times 2 \times 2 \times 3$ (genotype $\times$ treatment $\times$ order $\times$ difficulty) ANOVA revealed significant main effect of treatment $\left(\mathrm{F}(1,19)=7.5, p<0.013, \eta^{2}=0.284\right)$ and difficulty level $\left(\mathrm{F}(2,38)=5.2, p<0.017, \varepsilon=0.78, \eta^{2}=0.216\right)$ and $\mathrm{a}$ significant treatment $\times$ genotype $(\mathrm{F}(1,19)=5.2, p<0.034$, $\left.\eta^{2}=0.216\right)$ interaction but not genotype or order $(\mathrm{Fs}<1)$ main effects. Because of trend genotype effects on IQ, we repeated the analysis with IQ as the covariate. Following this ANCOVA, the critical treatment by genotype interaction was significant only at trend level $(\mathrm{F}(1,18)=3.8, p=0.06$, $\left.\eta^{2}=0.175\right)$. The treatment $\times$ genotype interaction was followed up with ANOVAs within each separate genotype group. In the $\mathrm{Val} / \mathrm{Val}$ group, there were significant treatment $(\mathrm{F}(1,10)=10.6, p<0.009))$ and difficulty $(\mathrm{F}(2,20,10)=4.96$, $p<0.042)$ main effects and a treatment $\times$ difficulty interaction $(\mathrm{F}(1,10)=3.9, p<0.04))$, indicating significant improvement in performance with tolcapone, especially at the more demanding 2- and 3-back levels of difficulty. In contrast, there were no significant main effects or interactions in the case of the Met/Met group.

Correct responses: the overall ANOVA revealed only an expected significant main effect of difficulty level $(\mathrm{F}(2,42)=7.2, \quad \varepsilon=0.626, \quad p<0.008) \quad($ all other $p>0.16$; Figure 4, middle).

Letter-number sequencing. Figure 4 (bottom) shows the correct responses for both groups under the two treatment conditions. The overall $2 \times 2 \times 2 \times 7 \quad$ (genotype $\times$ treatment $\times$ order $\times$ difficulty) ANOVA revealed significant main effects of treatment $\left(\mathrm{F}(1,19)=7.1, p<0.016, \eta^{2}=\right.$ $0.271)$ and difficulty level $(\mathrm{F}(6,114)=178.9, \quad \varepsilon=0.4$, $\left.p<0.000, \eta^{2}=0.904\right)$ and significant treatment $\times$ genotype $\left(\mathrm{F}(1,19)=4.4, p<0.05, \eta^{2}=0.189\right)$ and treatment $\times$ order $\left(\mathrm{F}(1,19)=7.1, p<0.016, \eta^{2}=0.271\right)$ interactions but not genotype $(F=1.15)$ or order $(F<1)$ main effects. The critical treatment by genotype interaction was significant only at trend level $\left(\mathrm{F}(1,18)=3.9, p=0.06, \eta^{2}=0.178\right)$ when IQ was included as a covariate. The treatment $\times$ genotype interaction was followed up with ANOVAs within each separate genotype group. These ANOVAs indicated a significant effect of treatment in the $\mathrm{Val} / \mathrm{Val}$ $(\mathrm{F}(1,10)=8.5, p<0.015))$ but not in the Met/Met group $(\mathrm{F}<1$; Figure 4 , bottom). 
Placebo

Tolcapone

VAL/VAL Group
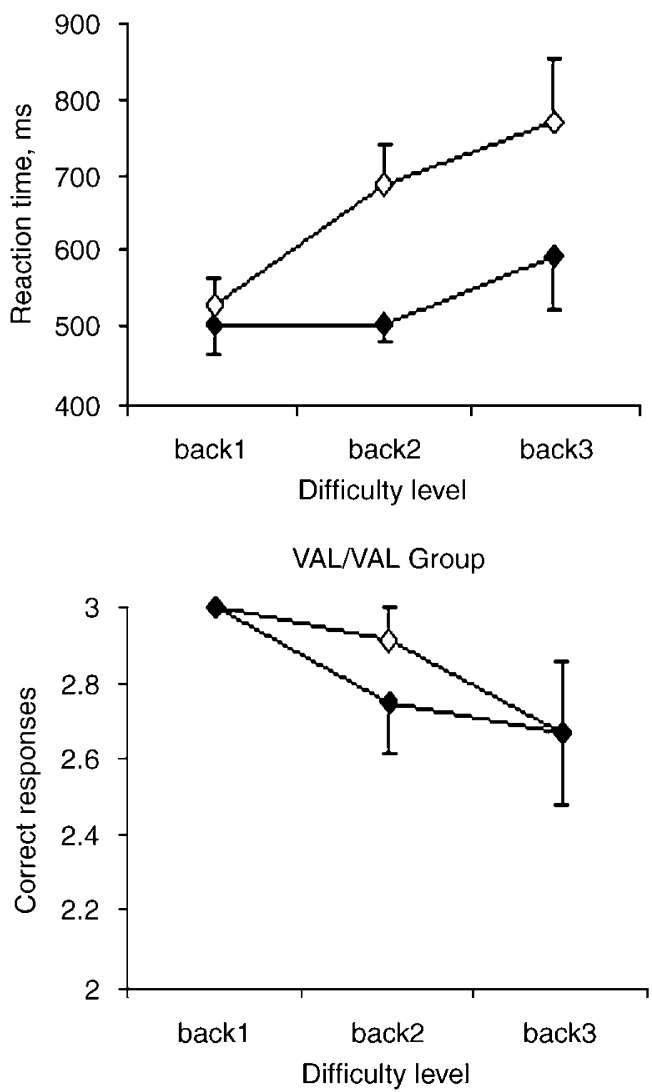

VAL/VAL Group

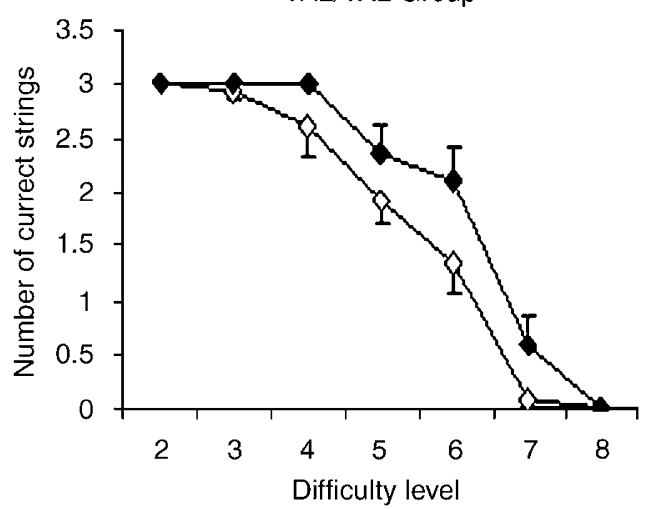

MET/MET Group
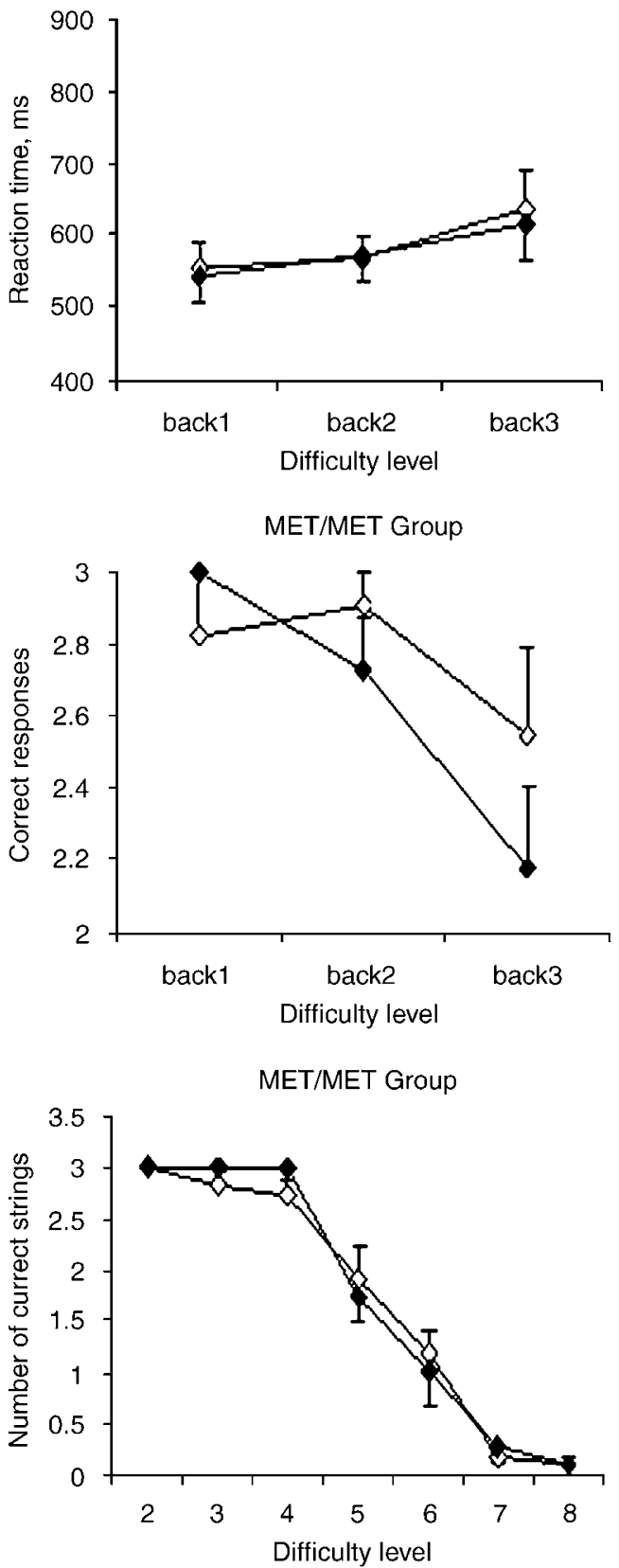

Figure 4 Reaction time (top) and correct responses (middle) for the n-back task and correct responses for the letter-number sequencing (LNS, bottom) for the two genotype groups under the two treatment conditions. Bars represent SEM.

As a further exploration of the relationship between the tolcapone effects on PPI and cognition, we also constructed a series of multiple regressions to assess whether variance in tolcapone-induced startle and PPI changes independently contributed to variance in tolcapone-induced effects on cognition. Placebo-tolcapone difference scores $(\Delta)$ for $n-$ back total reaction time and LNS total correct strings served as the dependent variables. Tolcapone-induced changes in $\%$ PPI $(\triangle \mathrm{PPI})$ at each trial type served as the independent variables. These regressions revealed that in the $\mathrm{Val} / \mathrm{Val}$ group, $\triangle \mathrm{PPI}$ at $85 \mathrm{~dB}$ per $60 \mathrm{~ms}$ trials significantly $(\mathrm{F}(1,10)=$ $8.4, p<0.016)$ ) explained $45.6 \%$ of the variance in $\Delta \mathrm{LNS}$ (total correct strings), whereas $53.6 \%$ of the variance in $\Delta$ n-back (total reaction time) was explained significantly $(\mathrm{F}(3,8)=6.5, p<0.02))$ by $\Delta \mathrm{PPI}$ at $85 \mathrm{~dB}$ per $60 \mathrm{~ms}, 85 \mathrm{~dB}$ per $30 \mathrm{~ms}$, and $75 \mathrm{~dB}$ per $30 \mathrm{~ms}$. Table 2 shows the Pearson's correlations between $\Delta$ scores in both working memory tests and $\Delta P P I$ and $\Delta$ pulse-alone in the entire sample. 
Table 2 Correlation Matrix Between Placebo-Tolcapone Difference $(\Delta)$ Scores of both Working Memory Tasks and $\Delta$ PPI at Six Trial Types, as well as $\Delta$ startle Amplitude in Pulse-Alone Trials

Pulse-

75_30 75_60 75_120 85_30 85_60 85_120 alone

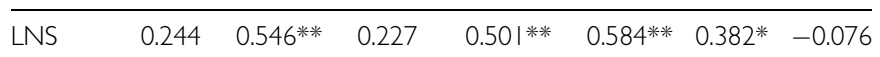

nBackRT $-0.283-0.354 *-0.359 *-0.219 \quad-0.384 * 0.061 \quad 0.248$

Abbreviations: LNS, letter-number sequencing (total correct strings); nBackRT, nBack total reaction time.

Values represent Pearson's correlation coefficients; * $p<0.05$; ** $p<0.007$

( $p$ correction for accumulation of $\alpha$ error $(0.05: 7)=0.007 \mid 4)$.

\section{DISCUSSION}

The present study provides first evidence of parallel improvement of working memory and PPI at short and long intervals specific to normal COMT Val158 homozygote subjects, after PFC DA increases by the COMT inhibitor tolcapone. More specifically, we found that tolcapone significantly increased PPI in Val158 homozygote subjects who have lower PFC DA levels and lower PPI than Met/Met subjects (Roussos et al, 2008a). We also found that tolcapone tended to have the opposite effect in Met/Met individuals. Similar to PPI, latency facilitation was also affected by tolcapone in a genotype-specific manner, only the Val/Val subjects reducing their time to peak with tolcapone. Comparison of the two groups for PPI in the placebo condition replicated the genotype differences in PPI (Roussos et al, 2008a) extending them to short, $30 \mathrm{~ms}$ intervals. These results confirm the importance of baseline PPI levels for the effect of dopaminergic drugs, which has been previously highlighted by different research groups (Swerdlow et al, 2003; Bitsios et al, 2005; Csomor et al, 2008) and strengthen our formulation of an interaction between PFC DA levels and PPI, according to an inverted U-shaped curve (Bitsios et al, 2005). These results also strengthen our previous suggestion that the PFC influences PPI levels, and by inference the early stages of attentional processing (Giakoumaki et al, 2006; Bitsios et al, 2006; Roussos et al, 2008a).

In perfect symmetry with our PPI findings, tolcapone also improved performance in two working memory tests only in Val158 but not in Met158 homozygotes. In the LNS where the sequencing of letters and numbers proceeds in an alternating fashion, we found that Val158 homozygotes had significantly more accurate responses following tolcapone administration. Replicating previous results (Apud et al, 2007), we also found that after tolcapone administration, the Val158 but not Met158 homozygotes were faster to respond correctly in the n-back task, especially with the hardest 2and 3-back high-load versions, in which updating of the working memory buffer is near continuous. These results extend recent findings showing that DA agonists such as amphetamine (Mattay et al, 2003) or relatively specific increases in PFC DA signaling by tolcapone (Apud et al, 2007) can lead to improved working memory performance in Val homozygotes who have suboptimal PFC DA levels; in contrast, the performance of Met homozygotes who have high PFC DA levels and stand near or at the top of the inverted U-shaped curve remains the same or may even deteriorate.

The similar pattern of tolcapone effects on PPI and working memory suggests (1) that PPI and working memory are closely linked and (2) the operation of a common underlying mechanism. The robust treatment by genotype effect observed in both PPI and working memory is consistent with relatively lower PFC DA signaling in Val/Val subjects and presumed benefit of enhanced PFC DA in this context (Weinberger et al, 2001; Egan et al, 2001; Mattay et al, 2003; Winterer and Goldman, 2003; Winterer et al, 2006). Notably, the improvement of PPI by tolcapone in the $\mathrm{Val} / \mathrm{Val}$ group, especially at short intervals, was found to account for a substantial part of the variance in tolcaponeinduced performance improvements in both working memory tests.

These observations aside, and despite empirical evidence that suggests that PPI may be critical for human cognition (Geyer et al, 1990), the present findings may reflect a common underlying circuit rather than a causal link between PPI and cognition. Although there is evidence for a close link between PFC DA activity and PPI in rodents (Bubser and Koch, 1994; Ellenbroek et al, 1996; Zavitsanou et al, 1999; Broersen et al, 1999; Lacroix et al, 2000) and the importance of PFC for PPI modulation in humans is rapidly accumulating (see 'Introduction'), PPI is regulated by a complex cortico-striato-pallido-pontine circuit (Swerdlow et al, 1992, 2001), in which the PFC is only one critical node. For instance, COMT is also expressed in the hippocampus (Matsumoto et al, 2003), which is also involved in PPI modulation (Swerdlow et al, 2001) and it is not known how COMT inhibition by tolcapone within the hippocampus may have influenced our results. Moreover, although the COMT Val158Met polymorphism determines basal PFC DA neurotransmission levels, it may also regulate striatal DA activity. Indeed, higher COMT activity, as conferred by the Val158 allele, is associated with elevated midbrain DA synthesis (Meyer-Lindenberg et al, 2005) and higher tyrosine-hydroxylase expression in neurons projecting to the striatum (Akil et al, 2003). This suggests that besides a direct reduction in cortical information processing resulting in less efficient executive cognition (eg working memory) the Val158 allele may indirectly increase striatal dopaminergic function, thus reducing PPI. On the other hand, the available evidence from the COMT literature (eg from COMT knockout mice) (Gogos et al, 1998; Huotari et al, 2002) argues for a definite role of the PFC vs striatum, favoring an impact particularly on cortical DA signaling and larger cortical than striatal effects in studies using COMT inhibitors. In the Val158 homozygotes, the tolcaponeinduced improvement of PPI at long (ie $120 \mathrm{~ms}$ ), more 'frontally mediated' intervals (Filion et al, 1993), is consistent with the known reduction of COMT activity by the drug, predominantly in the PFC, which presumably would lead to a boost of PFC DA and PFC function. However, the improvement of PPI at short 'preattentive' (ie $30 \mathrm{~ms}$ ) intervals cannot be easily attributed to such a direct PFC effect of the drug, as PPI at these short intervals is thought to be automatic and not a valid marker for PFC function (Schell et al, 2000). If, as mentioned above, high COMT activity as conferred by the Val158 is indeed associated with indirect increase in striatal dopaminergic 
function (Akil et al, 2003; Meyer-Lindenberg et al, 2005), then it is an intriguing possibility that reduction of COMT activity by tolcapone leads to reduction in striatal dopaminergic function, which may underlie the observed improvement in short lead PPI in Val158 homozygotes.

A more elaborate mechanism is drawn from the model put forward by Grace (1993)and Bilder et al (2004). This model posits that low tonic PFC DA levels (Val/Val subjects) may cause high phasic dopaminergic responses in the nucleus accumbens (NAC) and equally, high tonic PFC DA levels (Met/Met subjects) may cause low phasic DA responses in the NAC (Grace, 1993; Bilder et al, 2004). Low phasic (eg in response to a prepulse) DA levels within the NAC of Met/ Met subjects would result in greater activity in the startle inhibiting pedunculopontine tegmental nucleus (Swerdlow et al, 2001) and thus greater PPI levels. The opposite would be true for the Val/Val subjects. By tonically boosting PFC DA levels, tolcapone would improve both cognition and PPI at all intervals in $\mathrm{Val} / \mathrm{Val}$ subjects. Although admittedly speculative, we believe that at this moment, this view best explains all the available evidence, as it maintains tolcapone's prominent locus of action within the PFC, although it allows for meaningful interactions between the PFC and mesolimbic systems known to regulate PPI. Future research ought to examine DA release in the striatum during passive PPI paradigms at baseline and following tolcapone administration in Val158 and Met158 homozygotes. There have to be some common processes and neural regions involved in short and long lead PPI, as PPI at various short and long intervals correlates highly positively (Kumari et al, 2005, a, 2008). Certainly, more research is required on the effects of tolcapone on cognition and PPI with a greater range of intervals in passive and attentional paradigms and with other COMT polymorphisms.

Importantly, our findings were obtained from a homogeneous cohort of healthy male subjects and cannot be attributed to differences in gender, age, education, or startle characteristics. The magnitudes of the effects of tolcapone on working memory performance were relatively small and remained significant at trend level after covarying for the relatively large IQ genotype differences observed in this study. It is important to emphasize that our subjects were normal individuals without obvious deficits on these tasks and a 'ceiling effect' on performance is therefore built into our study, making the positive effects more remarkable. Also, our findings cannot be attributed to tolcapone effects on mood and activation, as there were no significant drug effects in any of the POMS measures. Tolcapone's beneficial effects on PPI and working memory in Val158 homozygotes were not accompanied by changes in activation and mood, suggesting that tolcapone was devoid of gross effects on the mesolimbic and mesostriatal dopaminergic systems in this group. This is consistent with evidence showing that COMT does not significantly affect extracellular DA levels in the rat striatum (Gogos et al, 1998; Li et al, 1998; Mazei et al, 2002; Tunbridge et al, 2004) and suggests that tolcapone's beneficial effects on PPI and cognition would be expected to occur in the absence of psychostimulant effects and abuse potential. The COMT enzyme of Val158 homozygotes may have more capacity to bind tolcapone because of its greater stability (Chen et al, 2004). Thus, it could be argued that the observed treatment $\times$ genotype interactions were merely a reflection of greater sensitivity to tolcapone of the $\mathrm{Val} / \mathrm{Val}$ individuals. Although this possibility cannot be totally excluded with regard to the effect of tolcapone on working memory, it is unlikely that it can account for our PPI findings, as tolcapone improved PPI in the $\mathrm{Val} / \mathrm{Val}$ group and affected the Met/Met group in the opposite way. Although the latter effect failed to reach significance, it is at odds with the above interpretation. It is possible that with a larger sample of Met/Met subjects a significant tolcaponeinduced PPI disruption could be detected in this group. More importantly, we obtained evidence for significant tolcapone bioactivity in the Met/Met group as documented in startle increases by the drug in Met158 but not in Val158 homozygotes.

The increase in startle by tolcapone in the Met158 but not Val158 homozygotes was unexpected and we do not have a definite explanation for it. Activation of the central noradrenergic and/or dopaminergic systems in rodents and humans is known to increase the startle reflex (Davis et al, 1979; Davis, 1985; Morgan et al, 1993). However, a putative effect of tolcapone on noradrenergic and/or dopaminergic neurotransmission within brainstem circuits mediating the startle reflex cannot easily explain the selective startle increase by the drug in the Met/Met group only. Startle reflex increases during negative mood (see Lang and Davis, 2006 for review), and Met homozygotes have reduced resilience against such negative mood states (Smolka et al, 2005; Drabant et al, 2006; Weiss et al, 2007). It is therefore possible that the startle increase by tolcapone in the Met/Met group is related to tolcapone-induced dysphoric mood in Met158 homozygotes. Although this is not supported by the subjective data, it is possible that startle, an automatic reflex response, is a more accurate and sensitive measure of dysphoric mood, independent of the slower, language-based appraisal processes (Lang et al, 2000). Certainly, more research is required on the interaction between tolcapone and COMT genotypes on emotional arousal and affective processing, using objective and specific paradigms such as the startle modulation by affective pictures (Lang et al, 1999).

PPI is a widely used surrogate measure of psychosis in animal models (Swerdlow et al, 1994). It is also considered a candidate endophenotype for schizophrenia (Braff and Light, 2005; Calkins et al, 2007) because of its high heritability (Anokhin et al, 2003; Greenwood et al, 2007) and the presence of PPI deficits in the unaffected firstdegree relatives of probands (Cadenhead et al, 2000; Kumari et al, 2005b). However, the genetic architecture of the PPI endophenotype is in its infancy. Two recent studies show two DA gene-specific influences on PPI levels that may explain observed individual differences (Roussos et al, $2008 \mathrm{a}, \mathrm{b}$ ). This is the first study on the enhancement of PPI and executive cognition by the nonstimulant tolcapone. Through specific manipulation of PFC DA, tolcapone offers a novel approach of 'targeted' pharmacology for the improvement of cognitive function and PPI, presumably by increasing DA-mediated prefrontal signal-to-noise ratio (Apud and Weinberger, 2007). The present study suggests that this novel pharmacological strategy may also be genotype targeted, as these effects were modified by COMT genotype. Our findings may have important implications for the treatment of disorders characterized by PFC 
dysfunction with deficient executive cognition and PPI such as schizophrenia.

\section{ACKNOWLEDGEMENTS}

This project was supported by the University of Crete Research Funds Account (ELKE 1348). SGG was supported by a 'Propondis Foundation' postdoctorate fellowship and PR was supported by a 'Manasaki' scholarship.

\section{DISCLOSURE/CONFLICT OF INTEREST}

All authors have no conflict of interest or any involvement, financial, or otherwise, that might have biased the present work.

\section{REFERENCES}

Akil M, Kolachana BS, Rothmond DA, Hyde TM, Weinberger DR, Kleinman JE (2003). Catechol-O-methyltransferase genotype and dopamine regulation in the human brain. $J$ Neurosci 23: 2008-2013.

Anokhin AP, Heath AC, Myers E, Ralano A, Wood S (2003). Genetic influences on prepulse inhibition of startle reflex in humans. Neurosci Lett 353: 45-48.

Apud JA, Mattay V, Chen J, Kolachana BS, Callicott JH, Rasetti R et al (2007). Tolcapone improves cognition and cortical information processing in normal human subjects. Neuropsychopharmacology 32: 1011-1020.

Apud JA, Weinberger DR (2007). Treatment of cognitive deficits associated with schizophrenia: potential role of catechol-Omethyltransferase inhibitors. CNS Drugs 21: 535-557.

Bilder RM, Volavka J, Lachman HM, Grace AA (2004). The catechol-O-methyltransferase polymorphism: relations to the tonic-phasic dopamine hypothesis and neuropsychiatric phenotypes. Neuropsychopharmacology 29: 1943-1961.

Bitsios P, Giakoumaki SG (2005). Relationship of prepulse inhibition of the startle reflex to attentional and executive mechanisms in man. Int J Psychophysiol 55: 229-241.

Bitsios P, Giakoumaki SG, Frangou S (2005). The effects of dopamine agonists on prepulse inhibition (PPI) in healthy males depend on baseline PPI values. Psychopharmacology 182: 144-152.

Bitsios P, Giakoumaki SG, Theou K, Frangou S (2006). Increased prepulse inhibition of the acoustic startle response is associated with better strategy formation and execution times in healthy males. Neuropsychologia 44: 2494-2499.

Braff DL, Geyer MA, Light GA, Sprock J, Perry W, Cadenhead KS et al (2001). Impact of prepulse characteristics on the detection of sensorimotor gating deficits in schizophrenia. Schizophr Res 49: 171-178.

Braff DL, Grillon C, Geyer MA (1992). Gating and habituation of the startle reflex in schizophrenic patients. Arch Gen Psychiatry 49: 206-215.

Braff DL, Light GA (2005). The use of neurophysiological endophenotypes to understand the genetic basis of schizophrenia. Dialogues Clin Neurosci 7: 125-135.

Braff DL, Light GA, Ellwanger J, Sprock J, Swerdlow NR (2005). Female schizophrenia patients have prepulse inhibition deficits. Biol Psychiatry 57: 817-820.

Braff DL, Stone C, Callaway E, Geyer MA, Glick I, Bali L (1978). Prestimulus effects on human startle reflex in normals and schizophrenics. Psychophysiology 15: 339-343.

Broersen LM, Feldon J, Weiner I (1999). Dissociative effects of apomorphine infusions into the medial prefrontal cortex of rats on latent inhibition, prepulse inhibition and amphetamineinduced locomotion. Neuroscience 94: 39-46.
Bubser M, Koch M (1994). Prepulse inhibition of the acoustic startle response of rats is reduced by 6-hydroxydopamine lesions of the medial prefrontal cortex. Psychopharmacology 113: 487-492.

Cadenhead KS, Swerdlow NR, Shafer KM, Diaz M, Braff DL (2000). Modulation of the startle response and startle laterality in relatives of schizophrenic patients and in subjects with schizotypal personality disorder: evidence of inhibitory deficits. Am J Psychiatry 157: 1660-1668.

Calkins ME, Dobie DJ, Cadenhead KS, Olincy A, Freedman R, Green MF et al (2007). The consortium on the genetics of endophenotypes in schizophrenia: model recruitment, assessment, and endophenotyping methods for a multisite collaboration. Schizophr Bull 33: 33-48.

Campbell LE, Hughes M, Budd TW, Cooper G, Fulham WR, Karayanidis F et al (2007). Primary and secondary neural networks of auditory prepulse inhibition: a functional magnetic resonance imaging study of sensorimotor gating of the human acoustic startle response. Eur J Neurosci 26: 2327-2333.

Ceravolo R, Piccini P, Bailey DL, Jorga KM, Bryson H, Brooks DJ (2002). 18F-dopa PET evidence that tolcapone acts as a central COMT inhibitor in Parkinson's disease. Synapse 43: 201-207.

Chen J, Lipska BK, Halim N, Ma QD, Matsumoto M, Melhem S et al (2004). Functional analysis of genetic variation in catechol-Omethyltransferase (COMT): effects on mRNA, protein, and enzyme activity in postmortem human brain. Am J Hum Genet 75: 807-821.

Cools R, Stefanova E, Barker RA, Robbins TW, Owen AM (2002). Dopaminergic modulation of high-level cognition in Parkinson's disease: the role of the prefrontal cortex revealed by PET. Brain 125: 584-594.

Csomor PA, Stadler RR, Feldon J, Yee BK, Geyer MA, Vollenweider FX (2008). Haloperidol differentially modulates prepulse inhibition and p50 suppression in healthy humans stratified for low and high gating levels. Neuropsychopharmacology 33: 497-512.

Da Prada M, Zurcher G, Kettler R, Colzi A (1991). New Therapeutic Strategies in Parkinson's Disease: Inhibition of MAO-B by Ro 19. 6327 and of COMT by Ro 40-7592. Plenum Press: New York.

Davis M (1985). Cocaine: excitatory effects on sensorimotor reactivity measured with acoustic startle. Psychopharmacology 86: $31-36$.

Davis M, Redmond Jr DE, Baraban JM (1979). Noradrenergic agonists and antagonists: effects on conditioned fear as measured by the potentiated startle paradigm. Psychopharmacology 65: 111-118.

Drabant EM, Hariri AR, Meyer-Lindenberg A, Munoz KE, Mattay VS, Weinberger DR et al (2006). Catechol-O-methyltransferase val158met genotype and neural mechanisms related to affective arousal and regulation. Arch Gen Psychiatry 63: 1396-1406.

Egan MF, Goldberg TE, Kolachana BS, Callicott JH, Mazzanti CM, Straub RE et al (2001). Effect of COMT Val108/158 Met genotype on frontal lobe function and risk for schizophrenia. Proc Natl Acad Sci USA 98: 6917-6922.

Ellenbroek BA, Budde S, Cools AR (1996). Prepulse inhibition and latent inhibition: the role of dopamine in the medial prefrontal cortex. Neuroscience 75: 535-542.

Filion DL, Dawson ME, Schell AM (1993). Modification of the acoustic startle-reflex eyeblink: a tool for investigating early and late attentional processes. Biol Psychol 35: 185-200.

Fletcher PC, Henson RN (2001). Frontal lobes and human memory: insights from functional neuroimaging. Brain 124: 849-881.

Geyer MA, Swerdlow NR, Mansbach RS, Braff DL (1990). Startle response models of sensorimotor gating and habituation deficits in schizophrenia. Brain Res Bull 25: 485-498.

Giakoumaki SG, Bitsios P, Frangou S (2006). The level of prepulse inhibition in healthy individuals may index cortical modulation of early information processing. Brain Res 1078: 168-170. 
Gogos JA, Morgan M, Luine V, Santha M, Ogawa S, Pfaff D et al (1998). Catechol-O-methyltransferase-deficient mice exhibit sexually dimorphic changes in catecholamine levels and behavior. Proc Natl Acad Sci USA 95: 9991-9996.

Goldman-Rakic PS (1998). The cortical dopamine system: role in memory and cognition. Adv Pharmacol 42: 707-711.

Grace AA (1993). Cortical regulation of subcortical dopamine systems and its possible relevance to schizophrenia. J Neural Transm 91: 111-134.

Greenwood TA, Braff DL, Light GA, Cadenhead KS, Calkins ME, Dobie DJ et al (2007). Initial heritability analyses of endophenotypic measures for schizophrenia: the consortium on the genetics of schizophrenia. Arch Gen Psychiatry 64: 1242-1250.

Hardman JG, Limbird LE, Goodman Gilman A (2001). The Pharmacological Basis of Therapeutics. McGraw-Hill: New York.

Harrison PJ, Weinberger DR (2005). Schizophrenia genes, gene expression, and neuropathology: on the matter of their convergence. Mol Psychiatry 10: 40-68.

Haut MW, Kuwabara H, Leach S, Arias RG (2000). Neural activation during performance of number-letter sequencing. Appl Neuropsychol 7: 237-242.

Huotari M, Gogos JA, Karayiorgou M, Koponen O, Forsberg M, Raasmaja A et al (2002). Brain catecholamine metabolism in catechol-O-methyltransferase (COMT)-deficient mice. Eur $J$ Neurosci 15: 246-256.

Karoum F, Chrapusta SJ, Egan MF (1994). 3-Methoxytyramine is the major metabolite of released dopamine in the rat frontal cortex: reassessment of the effects of antipsychotics on the dynamics of dopamine release and metabolism in the frontal cortex, nucleus accumbens, and striatum by a simple two pool model. J Neurochem 63: 972-979.

Kumari V, Antonova E, Geyer MA, ffytche D, Williams SC, Sharma T (2007). A fMRI investigation of startle gating deficits in schizophrenia patients treated with typical or atypical antipsychotics. Int J Neuropsychopharmacol 10: 463-477.

Kumari V, Antonova E, Zachariah E, Galea A, Aasen I, Ettinger U et al (2005). Structural brain correlates of prepulse inhibition of the acoustic startle response in healthy humans. NeuroImage 26: 1052-1058.

Kumari V, Das M, Zachariah E, Ettinger U, Sharma T (2005b). Reduced prepulse inhibition in unaffected siblings of schizophrenia patients. Psychophysiology 42: 588-594.

Kumari V, Ettinger U, Crawford TJ, Zachariah E, Sharma T (2005a). Lack of association between prepulse inhibition and antisaccadic deficits in chronic schizophrenia: implications for identification of schizophrenia endophenotypes. J Psychiatr Res 39: 227-240.

Kumari V, Fannon D, Geyer MA, Preethi Premkumar P, Simmons A, Kuipers E (2008). Cortical grey matter availability and sensorimotor gating in schizophrenia. Cortex. (in press).

Kumari V, Gray JA, Geyer MA, ffytche D, Soni W, Mitterschiffthaler MT et al (2003). Neural correlates of tactile prepulse inhibition: a functional MRI study in normal and schizophrenic subjects. Psychiatry Res 122: 99-113.

Lacroix L, Spinelli S, White W, Feldon J (2000). The effects of ibotenic acid lesions of the medial and lateral prefrontal cortex on latent inhibition, prepulse inhibition and amphetamineinduced hyperlocomotion. Neuroscience 97: 459-468.

Lang PJ, Bradley MM, Cuthbert B (1999). International Affective Picture System (IAPS): Technical Manual and Affective Ratings. The Center for Research in Psychophysiology: University of Florida, Gainesville, FL.

Lang PJ, Davis M (2006). Emotion, motivation, and the brain: reflex foundations in animal and human research. Prog Brain Res 156: 3-29.

Lang PJ, Davis M, Ohman A (2000). Fear and anxiety: animal models and human cognitive psychophysiology. J Affect Disord 61: 137-159.
Li YH, Wirth T, Huotari M, Laitinen K, MacDonald E, Mannisto PT (1998). No change of brain extracellular catecholamine levels after acute catechol-O-methyltransferase inhibition: a microdialysis study in anaesthetized rats. Eur J Pharmacol 356: 127137.

Matsumoto M, Weickert CS, Akil M, Lipska BK, Hyde TM, Herman MM et al (2003). Catechol $O$-methyltransferase mRNA expression in human and rat brain: evidence for a role in cortical neuronal function. Neuroscience 116: 127-137.

Mattay VS, Goldberg TE, Fera F, Hariri AR, Tessitore A, Egan MF (2003). Catechol $O$-methyltransferase Val158-Met genotype and individual variation in the brain response to amphetamine. Proc Natl Acad Sci USA 100: 6186-6191.

Mattay VS, Tessitore A, Callicott JH, Bertolino A, Goldberg TE, Chase TN et al (2002). Dopaminergic modulation of cortical function in patients with Parkinson's disease. Ann Neurol 51: 156-164.

Mazei MS, Pluto CP, Kirkbride B, Pehek EA (2002). Effects of catecholamine uptake blockers in the caudate-putamen and subregions of the medial prefrontal cortex of the rat. Brain Res 936: 58-67.

McNair D, Lorr M (1981). ITS Manual for the Profile of Mood States. Multi-health System Inc.: San Diego, CA.

Meyer-Lindenberg A, Kohn PD, Kolachana B, Kippenhan S, McInerney-Leo A, Nussbaum R et al (2005). Midbrain dopamine and prefrontal function in humans: interaction and modulation by COMT genotype. Nat Neurosci 8: 594-596.

Morgan CA, Southwick SM, Grillon C, Davis M, Krystal JH, Charney DS (1993). Yohimbine-facilitated acoustic startle reflex in humans. Psychopharmacology 110: 342-346.

Postma P, Gray JA, Sharma T, Geyer M, Mehrotra R, Das M et al (2006). A behavioural and functional neuroimaging investigation into the effects of nicotine on sensorimotor gating in healthy subjects and persons with schizophrenia. Psychopharmacology 184: 589-599.

Raven JC, Court JH, Raven J. (1977). Manual for Raven's Progressive Matrices and Vocabulary Scales. HK Lewis: London.

Roussos P, Giakoumaki SG, Bitsios P (2008b). The dopamine D(3) receptor Ser9Gly polymorphism modulates prepulse inhibition of the acoustic startle reflex. Biol Psychiatry, print copy in press (originally published online 5 March 2008, at http:// www.sciencedirect.com).

Roussos P, Giakoumaki SG, Rogdaki M, Pavlakis S, Frangou S, Bitsios P (2008a). Prepulse inhibition of the startle reflex depends on the catechol $o$-methyltransferase Val158Met gene polymorphism. Psychol Med 8: 1-8.

Schell AM, Wynn JK, Dawson ME, Sinaii N, Niebala CB (2000). Automatic and controlled attentional processes in startle eyeblink modification: effects of habituation of the prepulse. Psychophysiology 37: 409-417.

Smolka MN, Schumann G, Wrase J, Grusser SM, Flor H, Heinz A et al (2005). Catechol-O-methyltransferase val158met genotype affects processing of emotional stimuli in the amygdala and prefrontal cortex. J Neurosci 25: 836-842.

Swerdlow NR, Braff DL, Taaid N, Geyer MA (1994). Assessing the validity of an animal model of deficient sensorimotor gating in schizophrenic patients. Arch Gen Psychiatry 51: 139-154.

Swerdlow NR, Caine SB, Braff DL, Geyer MA (1992). Neural substrates of sensorimotor gating of the startle reflex: a review of recent findings and their implications. J Psychopharmacol 6: 176-190.

Swerdlow NR, Geyer MA, Braff DL (2001). Neural circuit regulation of prepulse inhibition of startle in the rat: current knowledge and future challenges. Psychopharmacology 156: 194-215.

Swerdlow NR, Light GA, Cadenhead KS, Sprock J, Hsieh MH, Braff DL (2006). Startle gating deficits in a large cohort of patients with schizophrenia: relationship to medications, symptoms, 
Tolcapone effects on PPI and cognition

SG Giakoumaki et al

neurocognition, and level of function. Arch Gen Psychiatry 63: $1325-1335$.

Swerdlow NR, Stephany N, Wasserman LC, Talledo J, Shoemaker J, Auerbach PP (2003). Amphetamine effects on prepulse inhibition across-species: replication and parametric extension. Neuropsychopharmacology 28: 640-650.

Tunbridge EM, Bannerman DM, Sharp T, Harrison PJ (2004). Catechol-O-methyltransferase inhibition improves set-shifting performance and elevates stimulated dopamine release in the rat prefrontal cortex. J Neurosci 24: 5331-5335.

Tunbridge EM, Harrison PJ, Weinberger DR (2006). Catechol-Omethyltransferase, cognition, and psychosis: Val158Met and beyond. Biol Psychiatry 60: 141-151.

Wechsler D (1997). Wechsler Adult Intelligence Scale-Third Revision (WAISIII). Psychological Corporation: San Antonio, TX.

Weinberger DR, Egan MF, Bertolino A, Callicott JH, Mattay VS, Lipska BK et al (2001). Prefrontal neurons and the genetics of schizophrenia. Biol Psychiatry 50: 825-844.
Weiss EM, Stadelmann E, Kohler CG, Brensinger CM, Nolan KA, Marksteiner J et al (2007). Differential effect of catechol-Omethyltransferase Val158Met genotype on emotional recognition abilities in healthy men and women. J Int Neuropsychol Soc 18: $1-7$.

Williams GV, Goldman-Rakic PS (1995). Modulation of memory fields by dopamine D1 receptors in prefrontal cortex. Nature 376: $572-575$.

Winterer G, Egan MF, Kolachana BS, Goldberg TE, Coppola R, Weinberger DR (2006). Prefrontal electrophysiologic 'noise' and catechol-O-methyltransferase genotype in schizophrenia. Biol Psychiatry 60: 578-584.

Winterer G, Goldman D (2003). Genetics of human prefrontal function. Brain Res Brain Res Rev 43: 134-163.

Zavitsanou K, Cranney J, Richardson R (1999). Dopamine antagonists in the orbital prefrontal cortex reduce prepulse inhibition of the acoustic startle response in rats. Pharmacol Biochem Behav 63: 55-61. 